\title{
High-grade glioma in elderly patients: can the oncogeriatrician help?
}

\author{
This article was published in the following Dove Press journal: \\ Clinical Interventions in Aging \\ 5 December 2013 \\ Number of times this article has been viewed
}

\author{
Emeline Tabouret ${ }^{\prime}$ \\ Louis Tassy ${ }^{2}$ \\ Olivier Chinot ${ }^{1}$ \\ Elodie Crétel ${ }^{3}$ \\ Frederique Retornaz ${ }^{4}$ \\ Frederique Rousseau ${ }^{5}$ \\ 'Department of Neuro-oncology, \\ Timone Hospital, Marseille, France; \\ ${ }^{2}$ Department of Medical Oncology, \\ Centre Léon Bérard, Lyon, France; \\ ${ }^{3}$ Transveral Oncogeriatric Unit, \\ University Hospital Timone, Marseille, \\ France; ${ }^{4}$ Departmental Gerontologic \\ Center, Marseille, France; \\ ${ }^{5}$ Department of Medical Oncology, \\ Institut Paoli Calmettes, Marseille, \\ France
}

\begin{abstract}
Gliomas are the most frequent primary brain tumors in adults. As the population ages in Western countries, the number of people being diagnosed with glioblastoma is expected to increase. Clinical management of elderly patients with primary brain tumors is difficult, owing to multiple comorbidities, polypharmacy, decreased tolerance to chemotherapy, and an increased risk of radiation-induced neurotoxicity. A few specific randomized studies have shown a benefit for radiotherapy in elderly patients with good performance status. For patients with poor performance status, chemotherapy (temozolomide) has been shown to be associated with prolonged duration of response. Patients with methylated $O^{6}$-alkylguanine deoxyribonucleic acid alkyltransferase promoter seem to have better outcomes. Oncogeriatrics proposes the geriatric evaluation of elderly patients to improve therapeutic choices and optimize the management of treatment toxicities and comorbidities.
\end{abstract}

Keywords: brain tumor, older cancer patient, chemotherapy toxicity, oncogeriatric charter

\section{Introduction}

Gliomas are the most frequent primary brain tumors in adults. Their prevalence is reported to be increasing in the elderly population. ${ }^{1,2}$ As the number of people in the seventh to ninth decades of life increases, the number of people diagnosed with glioblastoma multiforme (GBM) is expected to increase. Older age is known to be a negative clinical prognostic factor for glioma. ${ }^{3}$ Specific management of elderly patients remains controversial, because they are often excluded from clinical trials. However, recent advances in the diagnosis and therapeutic approaches of glioma, as well as biological advances, have led to the development of specific therapeutic approaches in elderly patients.

The goal of oncogeriatrics is twofold: to control the cancer in the most effective way possible, and preserve for as long as possible the autonomy of the elderly patient. To evaluate patients, the geriatrician can use the simplified geriatric evaluation (SGE). The SGE is based on the evaluation of medical problems (comorbidities) and the functional status (measurement of the patient's incapacities). The SGE also includes the evaluation of cognitive, psychosocial, nutritional, and environmental status. The role of the geriatrician in oncology differs depending on the type of tumor and the stage of the disease. In the case of glioblastoma, the prognosis of the disease often supersedes that of other age-related conditions. The role of the geriatrician is to improve the overall management of the patient and sometimes help determine which patients can receive aggressive treatment. The role also includes improving the management of side effects in this specific population. We performed a comprehensive review of the
Correspondence: Frederique Rousseau Department of Medical Oncology, Institut Paoli Calmettes, 232 Boulevard Sainte Marguerite, Marseille 13009, France Tel +3349122 3847

Fax +33491223856

Email rousseauf@ipc.unicancer.fr 
literature concerning biological, diagnostic, and therapeutic aspects of glioma in elderly patients.

\section{Diagnosis}

\section{Histological and molecular alterations}

Glioma tumor cells can be derived from neural stem cells, progenitor cells, or from dedifferentiated mature neural cells. However, the actual World Health Organization classification is based on the classification of mature cells and distinguishes between astrocytomas, oligodendrogliomas, and mixed oligoastrocytomas. ${ }^{4}$ Histological grading depends on tumor cell differentiation, cellularity, cytonuclear atypia, mitotic activity, microvascular proliferation, and necrosis, leading to the discernment of low-grade gliomas (grade II), anaplastic gliomas (grade III), and glioblastoma (grade IV) in order of increasing aggressiveness. The natural history of low-grade glioma is to progressively transform to grades III and IV.

Several molecular alterations have been identified. One of the most important is the $1 \mathrm{p} 19 \mathrm{q}$ codeletion, which has prognostic and predictive value in the progression of glioma., Tumors that contain this translocation of $19 \mathrm{q}$ to $1 \mathrm{p}$ have been shown to be associated with an oligodendroglial phenotype, a slower course of the disease, and a better response to chemotherapy. However, this molecular alteration has not been specifically evaluated in the elderly population.

Methylation of the $O^{6}$-alkylguanine deoxyribonucleic acid alkyltransferase (MGMT) promoter has been described to be associated with a better prognostic value and potentially a better response to alkylating agents. A study of 233 glioblastoma patients aged $\geq 70$ years found an MGMT methylation rate of $57.5 \%$. It seems that elderly patients with methylated MGMT tumors presented with longer progression-free survival (PFS) and overall survival (OS) and were more likely to benefit from chemotherapy. ${ }^{8}$

Isocitrate dehydrogenase $1(I D H 1)$ mutations have been reported to be expressed in low-grade, anaplastic glioma, and secondary glioblastoma. This mutation is associated with better clinical outcomes for patients. However, a recent molecular analysis performed in an elderly population revealed that only $2 \%$ of patients had the $I D H 1$ mutation, precluding the determination of an association between IDH mutation and outcome for these patients. ${ }^{9}$

Other molecular alterations have been reported by the Cancer Genome Atlas Research Network, providing new insights into the role of ERBB2, NF1, and TP53. ${ }^{10}$ Presence of the TP53 mutation and its overexpression is frequently associated with the astrocytic phenotype, but their prognostic implication remains unclear, as well as the implication of the epidermal growth factor receptor (EGFR) amplification observed in $45 \%$ of glioblastoma cases.

Recently, a histone mutation has been described in histone H3.3 (H3F3A), but this was absent in all elderly patients sequenced. ${ }^{9}$ This mutation seems to be positively associated with glioma of pediatric or young adult patients. Numerous other molecular alterations have been linked to glioma, such as the vascular endothelial growth-factor pathway, which is suspected to be increased in primary glioblastoma of older patients. ${ }^{11}$ These molecular alterations have been implicated in invasion, signal transduction, cell-cycle control, angiogenesis, and cell metabolism. Finally, altered expression levels of several micro-ribonucleic acids were identified in glioblastoma, representing promising therapeutic targets in this pathology. ${ }^{12}$

In elderly patients, the prevalence of MGMT methylation is of a similar level to that reported in young patients. The gliomas of elderly patients largely lack the favorable prognostic markers established in younger patients, which may explain the overall worse prognosis among elderly patients. ${ }^{9}$

\section{Epidemiology}

Gliomas account for $70 \%$ of primary brain tumors in adults, with an incidence of six cases per 100,000 patients per year. Glioblastomas represent approximately $50 \%$ of gliomas, while grade III (anaplastic) and grade II gliomas each represent $25 \%$ of other glioma tumor cases. ${ }^{13}$ Patients aged $\geq 65$ years represent a third of all glioblastoma patients, and their total number is increasing. ${ }^{1,2,14}$ Elderly people have been reported to have a 3.18-fold higher relative risk of brain tumor compared with young adults. ${ }^{14}$ Chakrabarti et $\mathrm{al}^{2}$ reported age-specific incidence rates among males aged 70-74 years and females aged 75-79 years and found that males had a $60 \%$ increased risk of brain tumors. Low-grade gliomas (grade II) are less frequent in the elderly population than in the younger population, and glioblastomas in elderly people represent one-third of total glioblastoma diagnosis. ${ }^{15}$ In this specific population, pilocytic astrocytomas are extremely rare. ${ }^{16}$

\section{Etiology}

The etiology of glioma is unknown in $\geq 90 \%$ of cases. Previous exposure to ionizing radiation is one of the few known risk factors. Radiofrequency electromagnetic fields emitted by mobile phones have been suspected as a risk factor. However, a recent epidemiological analysis did not find a correlation between mobile phone exposure and increased risk of glioma development. ${ }^{17}$ Genetic predisposition to glioma is a well-known risk factor, but this is rare and mainly 
affects young patients (eg, type 1 or type 2 neurofibromatosis, Li-Fraumeni syndrome, tuberous sclerosis, Turcot syndrome, Cowden syndrome).

\section{Clinical and radiological features}

There is a tendency among elderly patients to underestimate their symptoms, which are often attributed to aging or other preexistent pathologies. Clinical features can also be confusing and cause delays in diagnosis. In a retrospective study of 393 elderly glioblastoma patients, the most common symptoms at diagnosis were cognitive changes, language changes, and hemiparesis. ${ }^{18}$ Headache and seizure or intracranial hypertension were observed less often at the time of initial presentation. In $6 \%$ of patients, a fall was the first symptom. Differential diagnosis must be made with cognitive deterioration due to dementia or delirium due to other nonspecific medical conditions (eg, infection or pain). Few cases are asymptomatic, and patients are diagnosed using neuroimaging. ${ }^{18}$

Neuroimaging has improved during the last 20 years. ${ }^{19}$ Standard magnetic resonance imaging (MRI) remains the basic tool to diagnose glioma and monitor treatment response. Conventional $\mathrm{T}_{1}$ sequence with and without contrast and $\mathrm{T}_{2}$ /fluid-attenuated inversion recovery sequences remain the gold standard to describe new lesions and inform about malignancy criteria. Response evaluation is based on these MRI sequences, clinical symptoms, and steroid use. ${ }^{20}$ Recent MRI advances can improve the probability of tumor diagnosis with multimodal imaging, providing information about cellularity, metabolism, and angiogenesis of the lesion. Diffusion-weighted imaging can assess tumor cell density and differentiate brain tumors from brain abscesses. Proton magnetic resonance spectroscopy can estimate the proliferation rate of tumor cells ( $N$-acetylaspartate and choline) and necrosis (lipids or lactates). Perfusion MRI can assess the vascularization level of a lesion, providing information about the malignancy of the tumor. ${ }^{19}$ Another imaging approach consists of metabolism evaluation using positron emission tomography with radiolabeled tracers to detect high-grade malignancy, tumor recurrence, or residual disease after treatment.

\section{Prognostic factors}

The phenotype (astrocytic or oligodendrocytic) and grade are strongly correlated with outcome. In elderly patients with low-grade astrocytoma or oligodendroglioma, median OS is 9 and 57 months, respectively. For anaplastic glioma, median OS is between 4 and 9 months, according to the phenotype. ${ }^{21}$
The most important clinical prognostic factors remain age and performance status. ${ }^{3}$ Elderly patients have a worse prognosis compared with younger patients. ${ }^{22-24}$ Populationbased studies have shown that elderly patients are less likely to receive surgical resection, radiotherapy (RT), and adjuvant chemotherapy. Therapeutic approaches are directly influenced by the other prognostic factors (age, grade, Karnofsky performance status [KPS], and comorbidity). ${ }^{25,26}$ Worse prognosis in elderly glioblastoma patients may be linked to different patterns of care.

After Mohan et al in 1998, ${ }^{27}$ in 2003 Glantz et $\mathrm{al}^{28}$ confirmed that performance status scores of $<70$ in elderly glioblastoma patients (using the KPS approach) were associated with poorer survival. ${ }^{18}$ Since then, a KPS score of $>70$ has been the cornerstone used to develop clinical trials for elderly glioblastoma patients.

In a recursive partitioning analysis estimation, Scott et $\mathrm{al}^{29}$ identified in three cohorts of elderly glioblastoma patients four prognostic subgroups according to type of surgery, age $(>/<75)$, and KPS score $(>/<70)$.

\section{Management Surgery}

Surgery remains the first-line management strategy for primary cerebral tumors. Obtaining histological proof of the tumor is necessary to confirm diagnosis, determine the tumor subtype, and evaluate the occurrence of molecular alteration.

When possible, maximal resection is recommended for tumors as an initial treatment to reduce symptoms from mass effect and possibly to increase the efficacy of adjuvant treatments, thereby improving survival. In numerous studies concerning small retrospective or prospective cohorts of patients, the extent of resection is an important prognostic factor for elderly patients in correlation with PFS and OS. ${ }^{8,21,30,31}$

Neurosurgery in elderly patients is inherently risky, with postoperative hemorrhage occurring in $6 \%$ of elderly patients, ${ }^{24}$ which is more frequent than in younger patients. In a retrospective cohort study, Vuorinen et $\mathrm{al}^{32}$ reported the outcomes of 30 elderly patients undergoing biopsy or tumoral resection and found a significant difference in survival between the two groups. As this was not a randomized trial, the results were not conclusive. An ongoing French Phase III trial is addressing this important issue and evaluating the benefit of surgical resection versus biopsy in elderly patients.

A promising complementary surgical approach is the implantation of carmustine-containing polymers in the tumor 
bed during surgical resection. There are no specific data concerning this treatment in elderly patients, but some elderly patients have been included in several trials. ${ }^{33,34}$ In a French multicenter retrospective study including 163 patients, significant adverse events occurred in $44.6 \%$ of the population, including $6 \%$ with septic abscess. These complications could be more frequent or more severe in elderly patients. ${ }^{33}$

\section{Radiotherapy}

In 2007, a Phase III randomized trial conducted by KeimeGuibert et al ${ }^{35}$ showed that in elderly glioblastoma patients with good KPS scores $(>60)$, RT alone increased median survival by 3 months without altering the quality of life or the cognition of the patient, in comparison with the best supportive care. In this study, the RT schedule consisted of focal irradiation in daily fractions of $1.8 \mathrm{~Gy}$, which was administered 5 days per week, with a total dose of $50 \mathrm{~Gy}$. No severe adverse events related to RT were reported. Since then, RT alone has been considered the standard of care for fit elderly patients.

Hypofractionated RT is an interesting alternative for unfit elderly patients because it shortens treatment duration. Several retrospective or early prospective studies report the feasibility of this approach in elderly glioblastoma patients. ${ }^{36,37}$ Two RT schedules were compared in a Phase III randomized study: standard RT of $60 \mathrm{~Gy}$ in 30 fractions over 6 weeks versus a shorter course of RT of 40 Gy in 15 fractions over 3 weeks in elderly patients. There was no difference in survival between the two groups. ${ }^{38}$

\section{Chemotherapy}

For patients with poor KPS scores, temozolomide (TMZ) has been associated with prolonged response duration and favorable toxicity profile. ${ }^{39}$ The recent Phase II trial of the Association des NeuroOncologues d'Expression Française (ANOCEF) group evaluated the benefit of TMZ in elderly patients (aged $>70$ years) with poor performance status (KPS <70). TMZ was associated with an improvement of functional status in $33 \%$ of patients and with potential increased survival compared with supportive care alone, particularly for patients with methylated MGMT promoter. The toxicity profile has been shown to be acceptable, with mainly hematological toxicity. ${ }^{40} \mathrm{~A}$ more recent Phase III trial ${ }^{8}$ compared the benefit of chemotherapy alone (TMZ) versus RT alone for malignant astrocytoma in elderly patients. ${ }^{8}$ A total of 373 patients aged $\geq 65$ years with a KPS score $\geq 60$ were enrolled. There were no significant differences between the TMZ and RT groups in terms of event-free survival (EFS) and OS. In this study, MGMT promoter methylation was associated with longer OS. Moreover, EFS was longer in patients with MGMT promoter methylation who received TMZ than in those who underwent RT, whereas the opposite was true for patients without MGMT promoter methylation. Despite this, RT remains the standard of care for patients with KPS scores $\geq 70$. MGMT promoter methylation could be a useful predictive biomarker in this patient population. Another Phase III trial ${ }^{41}$ randomized patients aged $\geq 60$ years into three groups: those administered RT of 60 Gy in 30 fractions, those administered RT of 34 Gy in ten fractions; and those administered TMZ. In comparison with the standard RT schedule, median OS was significantly longer with TMZ (8.3 months versus 6.0 months) but not with hypofractionated RT (7.5 months). Similar results were found for patients aged $\geq 70$ years. A short course of RT should be preferred for elderly patients, and MGMT methylation status was an important prognostic factor for patients treated with TMZ.

A procarbazine, lomustine, and vincristine protocol was approved as a first-line therapy for anaplastic glioma, but was not specifically evaluated in elderly patients. ${ }^{5,6}$ Some of them have been included in retrospective and prospective trials. ${ }^{42}$ The toxicity profile was significantly worse, with severe hematological and neurological side effects.

At relapse, few drugs have been specifically evaluated. In a retrospective study of 65 selected elderly patients, fotemustine showed a disease-control rate of $43 \%$. However, this schedule was associated with significant hematological toxicity, thus limiting its routine use. ${ }^{43}$ Carmustine has a low response rate and limited hematological toxicity. ${ }^{44}$ Enhanced risk of hematological toxicity prevents its use in elderly patients. ${ }^{45}$

\section{Concomitant treatments}

After maximal resection, the standard of care for young patients is a combination of RT and concomitant and adjuvant TMZ. ${ }^{46}$ In elderly patients, this protocol was applied with or without doses of RT adaptation (Table 1). Preliminary results are encouraging, with good tolerance profiles. The pooled data of four prospective Phase II trials that included only elderly patients in good general health showed median PFS and OS of 10 and 13 months, respectively, with mild acute toxicity. ${ }^{47} \mathrm{RT}$ with concomitant and adjuvant TMZ for elderly patients was significantly associated with improvement or stability in most quality-of-life domains. ${ }^{48}$ This schedule is under investigation in an ongoing Phase III trial (National Cancer Institute of Canada [NCIC]/European Organisation for Research and Treatment of Cancer [EORTC]) comparing 
Table I Clinical studies evaluating concomitant and adjuvant radio-chemotherapy for elderly patients with glioblastoma

\begin{tabular}{|c|c|c|c|c|c|c|c|}
\hline Study & Year & Method & $\begin{array}{l}\text { Number } \\
\text { of patients }\end{array}$ & $\begin{array}{l}\text { Radiotherapy } \\
\text { schedule }\end{array}$ & $\begin{array}{l}\text { Median } \\
\text { PFS (months) }\end{array}$ & $\begin{array}{l}\text { Median } \\
\text { OS (months) }\end{array}$ & $\begin{array}{l}\text { Grade } 3 \text { or } 4 \\
\text { toxicity }\end{array}$ \\
\hline Minniti et $a^{60}$ & 2012 & Prospective & 71 & $40 \mathrm{~Gy}$ & 6 & 12.4 & $15 \%$ \\
\hline Minniti et $\mathrm{a}^{61}$ & 2009 & Prospective & 43 & $30 \mathrm{~Gy}$ & 6.3 & 9.3 & $28 \%$ \\
\hline Minniti et $\mathrm{al}^{62}$ & 2008 & Prospective & 32 & $60 \mathrm{~Gy}$ & 7 & 10.6 & $46 \%$ \\
\hline Brandes et $\mathrm{al}^{42}$ & 2003 & Prospective & 23 & $59.4 \mathrm{~Gy}$ & 10.7 & 14.9 & $7.70 \%$ \\
\hline Combs et $a^{63}$ & 2008 & Retrospective & 43 & $60 \mathrm{~Gy}$ & 4 & 11 & $9.30 \%$ \\
\hline Sijben et al ${ }^{64}$ & 2008 & Retrospective & 19 & $60 \mathrm{~Gy}$ & 6 & 8.5 & $42 \%$ \\
\hline Lee et $\mathrm{al}^{65}$ & 2013 & Retrospective & 20 & $60 \mathrm{~Gy}$ & - & 11.8 & $15 \%$ \\
\hline Fiorentino et $\mathrm{a}^{26}$ & 2012 & Retrospective & 35 & $60 \mathrm{~Gy}$ & 8 & 13 & $20 \%$ \\
\hline Floyd et al ${ }^{66}$ & 2012 & Prospective & 20 & $40 \mathrm{~Gy}$ & 11 & 13 & $0 \%$ \\
\hline
\end{tabular}

Abbreviations: PFS, progression-free survival; OS, overall survival.

a reduced course of RT of 40 Gy in 15 fractions versus the same schedule with concomitant and adjuvant TMZ in patients aged $\geq 65$ years with good performance status.

\section{Targeted therapy}

Among targeted therapies, bevacizumab shows very encouraging results in GBM and is under investigation in Phase III trials in a first-line setting in young patients (Roche-sponsored AVAglio [BO21990] and Radiation Therapy Oncology Group [RTOG] 0825). Preliminary results suggest a clinical benefit after bevacizumab administration for all patients in the elderly population. Two previous studies ${ }^{11,49}$ have reported a potential advantage in older patients in terms of survival. Our retrospective institutional study failed to reproduce similar results. ${ }^{50}$ Recent results of a French Phase II trial ${ }^{51}$ did not find benefits of bevacizumab in addition to TMZ for elderly patients with altered general status. The potential role of bevacizumab remains unknown among elderly patients.

\section{Supportive care}

Supportive care plays a major role in the management of glioma in elderly patients. Corticosteroids and antiepileptics (AEs) are mainly used in these patients to limit tumoral edema, improve functional status, and control headaches. Moreover, the corticosteroid dose is a marker of response in the response evaluation of Revised Assessment in Neurooncology criteria as a surrogate marker of tumor behavior and cerebral tolerance. In elderly patients, long-term corticosteroid treatment is associated with severe systemic complications (mainly osteoporosis [16\%] and hypertension [12\%], but also diabetes and psychiatric problems). ${ }^{52}$

AEs are systematically used for a short time after cerebral surgical resection of a lesion. There is no indication for systematic use of AEs for primary prevention in patients with no history of seizures. However, in cases of seizure linked to tumoral process, use of AEs is mandatory. A recent publication has reported a potential beneficial effect of valproate acid, depending on histone deacetylases-inhibitor effect of this AE. Valproate acid use during RT for GBM was associated with improved OS, independently of RTOG recursive partitioning analysis, seizure history, and concurrent TMZ use. ${ }^{53}$

\section{Individual patient factors}

Besides the tumor itself (location, type, histological grading, genetic modifications [deletion at 1p19q and MGMT promoter methylation]), patients' individual characteristics are very important factors in defining the therapeutic strategy in elderly glioblastoma patients.

One of the most important decisional markers is the performance status, assessed using the KPS index..$^{54}$ For older patient with KPS scores $>70$, RT is the standard treatment, ${ }^{35}$ whereas for those with altered health status (KPS score $<70$ ), chemotherapy alone is recommended..$^{39,40}$

Comorbidities and medical history of patients impact therapeutic decisions, particularly in elderly patients. RT can induce a progressive decline in attentional functioning. ${ }^{55}$ Neurological radiotoxicity (progressive decline in attentional functioning after cerebral radiotherapy) ${ }^{55}$ is increased in elderly patients, particularly in those with cardiovascular history. In this population, chemotherapy is the preferred treatment option.

Age and comorbidities impact surgical decisions: anticoagulant or antiaggregate treatment can preclude elderly patients from surgery. Moreover, elderly patients may be more strongly exposed to side effects of GA.$^{56,57}$ Some comorbidities preclude elderly patients from receiving chemotherapy (eg, dysmyelopoietic syndrome, myeloid anomalies, and renal or hepatic disorders), while bevacizumab is prohibited in cases of embolic events or those with a history of arterial disorders.

Principal drug interactions implicate AE treatment, some of which are enzymatic inductors. These characteristics lead 
to slower efficacy of chemotherapy and require specific dosage adaptations. These modifications are not specific to elderly patients, but could be more inconvenient for them.

Elderly patients with multiple pathologies and multiple medications are at high risk for adverse drug events. ${ }^{58}$ Principal drug interactions in glioblastoma patients are related to AEs and corticosteroids. As enzymatic inductors, AE treatments can alter the efficiency and toxicity of chemotherapy and may require specific dosage adjustments.

\section{Future perspectives}

The treatment of glioblastoma in elderly patients is expected to progress, with new treatments (eg, targeted therapy combined with chemotherapy), combinations of treatments, and new treatment strategies (eg, a specific vaccine against a mutated oncogene [EGFRvIII], which showed promising results in a Phase II trial). Only specific clinical trials designed for elderly patients can enable such progress.

To improve further the management of elderly glioblastoma patients, the geriatrician's involvement is required. Comprehensive geriatric evaluation (CGE) can assess elderly patients, who tend to be more heterogeneous than their younger counterparts, not only owing to comorbidities and physical and psychological disabilities but also owing to the generally poorer social and economic conditions under which they live. These factors make their assessment, diagnosis, prognosis, and treatment more difficult.

At the time of initial diagnosis, CGE can help to define elderly patients more accurately than the KPS score. Patients with recent functional impairment linked to the tumor itself and few comorbidities could be treated aggressively, even if their KPS score is poor. However, frail patients with previous loss of autonomy linked to severe comorbidities should be recommended less aggressive treatments.

During the course of treatment, the geriatrician can help to manage polypharmacy and drug interactions, thus limiting iatrogenic events, which are frequent in elderly patients. The geriatricians with their global approach toward patients, including the social environment and carers, can play an important role in maintaining quality of life in elderly glioma patients.

To improve further the management of elderly cancer patients in Marseille, the OncoGeriatric Coordination Unit (UCOG) has issued general guidelines of conduct and basic clinical practice, ${ }^{58,59}$ ie, the "OncoGeriatric Charter". This charter is adopted by UCOG's coordinators and health institutions and is available via the Internet to all facilities and services who are interested. Helping to homogenize practices in elderly cancer patients, the OncoGeriatric Charter is a step toward a true collaboration between geriatricians and oncologists to the benefit of elderly patients.

\section{Disclosure}

The authors report no conflicts of interest in this work.

\section{References}

1. Greig NH, Ries LG, Yancik R, Rapoport SI. Increasing annual incidence of primary malignant brain tumors in the elderly. J Natl Cancer Inst. 1990;82:1621-1624.

2. Chakrabarti I, Cockburn M, Cozen W, Wang YP, Preston-Martin S. A population-based description of glioblastoma multiforme in Los Angeles County, 1974-1999. Cancer. 2005;104:2798-2806.

3. Curran WJ Jr, Scott CB, Horton J, et al. Recursive partitioning analysis of prognostic factors in three Radiation Therapy Oncology Group malignant glioma trials. J Natl Cancer Inst. 1993;85:704-710.

4. Louis DN, Ohgaki H, Wiestler OD, et al. The 2007 WHO classification of tumours of the central nervous system. Acta Neuropathol. 2007;114: 97-109.

5. Cairncross G, Wang M, Shaw E, et al. Phase III trial of chemoradiotherapy for anaplastic oligodendroglioma: long-term results of RTOG 9402. J Clin Oncol. 2012;31:337-343.

6. van den Bent MJ, Brandes AA, Taphoorn MJ, et al. Adjuvant procarbazine, lomustine, and vincristine chemotherapy in newly diagnosed anaplastic oligodendroglioma: long-term follow-up of EORTC brain tumor group study 26951. J Clin Oncol. 2012;31:344-350.

7. Reifenberger G, Hentschel B, Felsberg J, et al. Predictive impact of MGMT promoter methylation in glioblastoma of the elderly. Int $J$ Cancer. 2012;131:1342-1350.

8. Wick W, Platten M, Meisner C, et al. Temozolomide chemotherapy alone versus radiotherapy alone for malignant astrocytoma in the elderly: the NOA-08 randomised, phase 3 trial. Lancet Oncol. 2009;13: 707-715.

9. Wiestler B, Claus R, Hartlieb SA, et al. Malignant astrocytomas of elderly patients lack favorable molecular markers: an analysis of the NOA-08 study collective. Neuro Oncol. 2013;15:1017-1026.

10. Cancer Genome Atlas Research Network. Comprehensive genomic characterization defines human glioblastoma genes and core pathways. Nature. 2008;455:1061-1068

11. Nghiemphu PL, Liu W, Lee Y, et al. Bevacizumab and chemotherapy for recurrent glioblastoma: a single-institution experience. Neurology. 2009;72:1217-1222.

12. Sana J, Hajduch M, Michalek J, Vyzula R, Slaby O. MicroRNAs and glioblastoma: roles in core signalling pathways and potential clinical implications. J Cell Mol Med. 2011;15:1636-1644.

13. Ricard D, Idbaih A, Ducray F, Lahutte M, Hoang-Xuan K, Delattre JY. Primary brain tumours in adults. Lancet. 2012;379:1984-1996.

14. Deorah S, Lynch CF, Sibenaller ZA, Ryken TC. Trends in brain cancer incidence and survival in the United States: Surveillance, Epidemiology, and End Results Program, 1973 to 2001. Neurosurg Focus. 2006;20:E1.

15. Lowry JK, Snyder JJ, Lowry PW. Brain tumors in the elderly: recent trends in a Minnesota cohort study. Arch Neurol. 1998;55:922-928.

16. Burkhardt K, Heuberger F, Delavelle J. Pilocytic astrocytoma in the elderly. Clin Neuropathol. 2007;26:306-310.

17. Benson VS, Pirie K, Schüz J, Reeves GK, Beral V, Green J. Mobile phone use and risk of brain neoplasms and other cancers: prospective study. Int J Epidemiol. 2013;42:792-802

18. Iwamoto FM, Cooper AR, Reiner AS, Nayak L, Abrey LE. Glioblastoma in the elderly: the Memorial Sloan-Kettering Cancer Center Experience (1997-2007). Cancer. 2009;115:3758-3766.

19. Dhermain FG, Hau P, Lanfermann H, Jacobs AH, van den Bent MJ. Advanced MRI and PET imaging for assessment of treatment response in patients with gliomas. Lancet Neurol. 2010;9:906-920. 
20. Wen PY, Macdonald DR, Reardon DA, et al. Updated response assessment criteria for high-grade gliomas: response assessment in neuro-oncology working group. J Clin Oncol. 2010;28:1963-1972.

21. Iwamoto FM, Reiner AS, Nayak L, Panageas KS, Elkin EB, Abrey LE. Prognosis and patterns of care in elderly patients with glioma. Cancer. 2009;115:5534-5540.

22. Lutterbach J, Bartelt S, Momm F, Becker G, Frommhold H, Ostertag C. Is older age associated with a worse prognosis due to different patterns of care? A long-term study of 1346 patients with glioblastomas or brain metastases. Cancer. 2005;103:1234-1244.

23. Villà S, Viñolas N, Verger E, et al. Efficacy of radiotherapy for malignant gliomas in elderly patients. Int J Radiat Oncol Biol Phys. 1998;42: 977-980.

24. Tanaka S, Meyer FB, Buckner JC, Uhm JH, Yan ES, Parney IF Presentation, management, and outcome of newly diagnosed glioblastoma in elderly patients. J Neurosurg. 2013;118:786-798.

25. Iwamoto FM, Reiner AS, Panageas KS, Elkin EB, Abrey LE. Patterns of care in elderly glioblastoma patients. Ann Neurol. 2008;64:628-634.

26. Fiorentino A, Caivano R, Chiumento C, et al. Comorbidity assessment and adjuvant radiochemotherapy in elderly affected by glioblastoma. Med Oncol. 2012;29:3467-3471.

27. Mohan DS, Suh JH, Phan JL, Kupelian PA, Cohen BH, Barnett GH. Outcome in elderly patients undergoing definitive surgery and radiation therapy for supratentorial glioblastoma multiforme at a tertiary care institution. Int J Radiat Oncol Biol Phys. 1998;42: 981-987.

28. Glantz M, Chamberlain M, Liu Q, Litofsky NS, Recht LD. Temozolomide as an alternative to irradiation for elderly patients with newly diagnosed malignant gliomas. Cancer. 2003;97:2262-2266.

29. Scott JG, Bauchet L, Fraum TJ, et al. Recursive partitioning analysis of prognostic factors for glioblastoma patients aged 70 years or older. Cancer. 2012;118:5595-5600.

30. Simpson JR, Horton J, Scott C, et al. Influence of location and extent of surgical resection on survival of patients with glioblastoma multiforme: results of three consecutive Radiation Therapy Oncology Group (RTOG) clinical trials. Int J Radiat Oncol Biol Phys. 1993;26:239-244.

31. Martinez R, Janka M, Soldner F, Behr R. Gross-total resection of malignant gliomas in elderly patients: implications in survival. Zentralbl Neurochir. 2007;68:176-181.

32. Vuorinen V, Hinkka S, Färkkilä M, Jääskeläinen J. Debulking or biopsy of malignant glioma in elderly people - a randomised study. Acta Neurochir (Wien). 2003;145:5-10.

33. Menei P, Metellus P, Parot-Schinkel E, et al. Biodegradable carmustine wafers (Gliadel) alone or in combination with chemoradiotherapy: the French experience. Ann Surg Oncol. 2010;17:1740-1746.

34. Westphal M, Hilt DC, Bortey E, et al. A phase 3 trial of local chemotherapy with biodegradable carmustine (BCNU) wafers (Gliadel wafers) in patients with primary malignant glioma. Neuro Oncol. 2003;5: 79-88.

35. Keime-Guibert F, Chinot O, Taillandier L, et al. Radiotherapy for glioblastoma in the elderly. $N$ Engl J Med. 2007;356:1527-1535.

36. Donato V, Monaco A, Rollo A, et al. Elderly and poor prognosis patients with high grade glioma: hypofractionated radiotherapy. Clin Ter. 2007; 158:227-230.

37. Hoegler DB, Davey P. A prospective study of short course radiotherapy in elderly patients with malignant glioma. J Neurooncol. 1997;33: 201-204.

38. Roa W, Brasher PM, Bauman G, et al. Abbreviated course of radiation therapy in older patients with glioblastoma multiforme: a prospective randomized clinical trial. J Clin Oncol. 2004;22:1583-1588.

39. Chinot OL, Barrie M, Frauger E, et al. Phase II study of temozolomide without radiotherapy in newly diagnosed glioblastoma multiforme in an elderly populations. Cancer. 2004;100:2208-2214.

40. Gállego Pérez-Larraya J, Ducray F, Chinot O, et al. Temozolomide in elderly patients with newly diagnosed glioblastoma and poor performance status: an ANOCEF phase II trial. J Clin Oncol. 2011;29: 3050-3055.
41. Malmström A, Grønberg BH, Marosi C, et al. Temozolomide versus standard 6-week radiotherapy versus hypofractionated radiotherapy in patients older than 60 years with glioblastoma: the Nordic randomised, phase 3 trial. Lancet Oncol. 2012;13:916-926.

42. Brandes AA, Vastola F, Basso U, et al. A prospective study on glioblastoma in the elderly. Cancer. 2003;97:657-662.

43. Santoni M, Scoccianti S, Lolli I, et al. Efficacy and safety of secondline fotemustine in elderly patients with recurrent glioblastoma. J Neurooncol. 2013;113:397-401.

44. Reithmeier T, Graf E, Piroth T, Trippel M, Pinsker MO, Nikkhah G. BCNU for recurrent glioblastoma multiforme: efficacy, toxicity and prognostic factors. BMC Cancer. 2010;10:30.

45. Grant R, Liang BC, Page MA, Crane DL, Greenberg HS, Junck L. Age influences chemotherapy response in astrocytomas. Neurology. 1995;45: 929-933.

46. Stupp R, Mason WP, van den Bent MJ, et al. Radiotherapy plus concomitant and adjuvant temozolomide for glioblastoma. $N$ Engl J Med. 2005;352:987-996.

47. Fiorentino A, Balducci M, De Bonis P, et al. Can elderly patients with newly diagnosed glioblastoma be enrolled in radiochemotherapy trials? Am J Clin Oncol. Epub February 5, 2013.

48. Minniti G, Scaringi C, Baldoni A, et al. Health-related quality of life in elderly patients with newly diagnosed glioblastoma treated with shortcourse radiation therapy plus concomitant and adjuvant temozolomide. Int J Radiat Oncol Biol Phys. 2013;86:285-291.

49. Kreisl TN, Kim L, Moore K, et al. Phase II trial of singleagent bevacizumab followed by bevacizumab plus irinotecan at tumor progression in recurrent glioblastoma. J Clin Oncol. 2009;27:740-745

50. Tabouret E, Barrie M, Thiebaut A, et al. Limited impact of prognostic factors in patients with recurrent glioblastoma multiforme treated with a bevacizumab-based regimen. $J$ Neurooncol. 2013;114:191-198.

51. Ahn GO, Brown JM. Role of endothelial progenitors and other bone marrow-derived cells in the development of the tumor vasculature. Angiogenesis. 2009;12:159-164.

52. Thomas TP. The complications of systemic corticosteroid therapy in the elderly. A retrospective study. Gerontology. 1984;30:60-65.

53. Kerkhof M, Dielemans JC, van Breemen MS, et al. Effect of valproic acid on seizure control and on survival in patients with glioblastoma multiforme. Neuro Oncol. 2013;15:961-967.

54. Karnofsky DA. Chemotherapy of neoplastic disease; agents of clinical value. N Engl J Med. 1948;239:299-305.

55. Douw L, Klein M, Fagel SS, et al. Cognitive and radiological effects of radiotherapy in patients with low-grade glioma: long-term follow-up. Lancet Neurol. 2009;8:810-818.

56. Audisio RA, Gennari R, Sunouchi K, et al. Preoperative assessment of cancer in elderly patients: a pilot study. Support Cancer Ther. 2003;1: 55-60.

57. Ramesh HS, Boase T, Audisio RA. Risk assessment for cancer surgery in elderly patients. Clin Interv Aging. 2006;1:221-227.

58. Cecile M, Seux V, Pauly V, et al. [Adverse drug events in hospitalized elderly patients in a geriatric medicine unit: study of prevalence and risk factors]. Rev Med Interne. 2009;30:393-400. French.

59. Hegi ME, Diserens AC, Gorlia T, et al. MGMT gene silencing and benefit from temozolomide in glioblastoma. N Engl J Med. 2005;352: 997-1003.

60. Minniti G, Lanzetta G, Scaringi C, et al. Phase II study of short-course radiotherapy plus concomitant and adjuvant temozolomide in elderly patients with glioblastoma. Int J Radiat Oncol Biol Phys. 2012;83: 93-99.

61. Minniti G, De Sanctis V, Muni R, et al. Hypofractionated radiotherapy followed by adjuvant chemotherapy with temozolomide in elderly patients with glioblastoma. J Neurooncol. 2009;91:95-100.

62. Minniti G, De Sanctis V, Muni R, et al. Radiotherapy plus concomitant and adjuvant temozolomide for glioblastoma in elderly patients. $J \mathrm{Neu}$ rooncol. 2008;88:97-103. 
63. Combs SE, Wagner J, Bischof M, et al. Postoperative treatment of primary glioblastoma multiforme with radiation and concomitant temozolomide in elderly patients. Int J Radiat Oncol Biol Phys. 2008;70: 987-992.

64. Sijben AE, McIntyre JB, Roldan GB, et al. Toxicity from chemoradiotherapy in older patients with glioblastoma multiforme. J Neurooncol. 2008;89:97-103.

65. Lee JH, Jung TY, Jung S, et al. Performance status during and after radiotherapy plus concomitant and adjuvant temozolomide in elderly patients with glioblastoma multiforme. J Clin Neurosci. 2013;20: 503-508.
66. Floyd SR, Kasper EM, Uhlmann EJ, Fonkem E, Wong ET, Mahadevan A. Hypofractionated radiotherapy and stereotactic boost with concurrent and adjuvant temozolamide for glioblastoma in good performance status elderly patients - early results of a Phase II trial. Front Oncol. 2012;2:122.

\section{Publish your work in this journal}

Clinical Interventions in Aging is an international, peer-reviewed journal focusing on evidence-based reports on the value or lack thereof of treatments intended to prevent or delay the onset of maladaptive correlates of aging in human beings. This journal is indexed on PubMed Central, MedLine, the American Chemical Society's 'Chemical Abstracts
Service' (CAS), Scopus and the Elsevier Bibliographic databases. The manuscript management system is completely online and includes a very quick and fair peer-review system, which is all easy to use. Visit http://www.dovepress.com/testimonials.php to read real quotes from published authors.

Submit your manuscript here: http://www.dovepress.com/clinical-interventions-in-aging-journal 